\title{
Standard versus Flywheel-Based Resistive Exercise
}

\section{JF Caruso*}

Exercise and Sports Science Program, The University of Tulsa, Tulsa, Oklahoma, USA

Resistive exercise is an increasingly popular modality to improve numerous performance and health-related outcomes. Due to its popularity and the results it provides, greater numbers of persons utilize resistive exercise to attain a myriad of benefits. While standard resistive exercise equipment has proved useful for a variety of fitness goals, some perceive drawbacks to this modality. Persons reluctant to use standard (barbells, dumbbells, etc.) resistive exercise equipment claim such devices are awkward and intimidating to use. Such persons include disuse models (cancer, HIV, aging, space flight, etc.) for whom resistive exercise may substantially improve their condition. Due to the prevalence of disuse models in modern society, their collective reticence towards standard equipment undermines their health and contributes towards a vast financial healthcare burden [1]. Newer resistive exercise equipment that requires less physical coordination and training to operate includes flywheel-based devices. Mounted onto the axles of exercise machines, the flywheel's radii dictate the magnitude of forces required to cause their rotation in order to complete repetitions. Since muscle forces and not Earth's gravitational pull impact flywheel rotation rates, such machines may be used during space flight to abate the adverse physical changes seen in astronauts. Flywheel-based machines offer concentric and eccentric resistance; unlike standard equipment, the kinetic energy imparted as muscles shorten dictates the magnitude of the muscle-lengthening load on the former device. This is contrary to the manner the standard resistive exercise devices operate; training adaptations from these two types of equipment may therefore yield divergent outcomes. Thus some question are, which type of resistive exercise equipment yields better results.

Perhaps the most thoroughly examined outcomes associated with resistive exercise relate to changes in muscle mass and strength [2]. Standard resistive exercise is a well-established modality to augment muscle mass and strength accretion in ambulatory subjects [2]. In disuse models, research has also examined the ability of resistive exercise to attenuate mass and strength losses which compromise muscle function and overall health $[3,4]$. For instance from a lack of physical activity, the elderly may incur large sarcopenia $(\sim 16 \%)$ and strength losses $(\sim 24 \%)$ over time which acts as a predictor of their survival [5]. Without gravity in outer space, losses to astronauts are of a similar magnitude to those of the elderly yet they occur at much faster rates [5]. Since they have the capability to operate without gravity, flywheelbased resistive exercise was also examined for its ability to reduce muscle mass and strength losses in space flight analogs. Significant knee extensor strength gains occurred in ambulatory elderly subjects who received a flywheel-based seated leg press intervention for ten weeks [6]. Flywheel-based resistive exercise interventions, administered concurrent to bed rest periods that ranged from 29-90 days, preserved knee extensor mass and elicited strength gains up to $7.7 \%$ higher than pre-unloading values [7-9]. One study even noted hypertrophy to bed rested muscle that received a concurrent flywheel-based exercise intervention [9]. Yet other flywheel-based trials had different results $[10,11]$. Administered concurrent to a 40 -day period of unilateral limb suspension, whereby one leg refrains from normal weight-bearing in human subjects, a flywheel-based seated leg press intervention still led to significant $(-10 \%)$ concentric strength losses to the unloaded knee extensors [11]. In similar fashion, a flywheel-based seated calf press intervention yielded significant unloaded ankle extensor strength losses ( 13-15\%) after a 40-day period of unilateral limb suspension
[10]. Yet with concurrent administration of the $\beta_{2}$ adrenergic agonist albuterol $\left(16 \mathrm{mgd}^{-1}\right)$, flywheel-based exercise evoked strength gains in unloaded limb muscles after the 40 days $[10,11]$. While flywheel-based exercise evokes strength gains in ambulatory subjects [6], data derived from unloaded muscle are equivocal [7-11].

Another important outcome associated with resistive exercise includes bone health and integrity. Ambulatory subjects treated with resistive exercise interventions with workouts on standard equipment incurred bone mineral content and density gains [6]. Research then proceeded to examine if similar types of changes could occur in disuse models. A 17-week human bed rest study showed a concurrent resistive exercise intervention on standard equipment produced better lumbar spine, hip and pelvis bone mineral density values as compared to unloaded control subjects [12]. Yet it was questioned if such improvements could be achieved with flywheel-based resistive exercise hardware [12,13]. Data from ambulatory men confirms this concern [14]. After 16 weeks whereby subjects were randomized to a treatment with no crossover, inter-group strength and muscle mass gains were similar, yet workouts done on standard equipment evoked significant lumbar bone mineral density gains while a flywheel-based paradigm elicited no changes [14]. It was concluded that flywheel-based devices did not offer a sufficient loading stimulus for bone [14]. A study with ambulatory elderly subjects noted similar effects [6]. The comparative effects of standard and flywheel-based resistive exercise were examined from a ten-week matched-pairs intervention with no crossover [6]. Both groups incurred significant strength and body composition improvements over time, yet workouts done with standard equipment evoked significant leg and total-body bone mineral density gains, while flywheel-based exercise led to no bone-related changes [6]. Changes to bone and muscle appear to differ with the type of equipment used [6]. Unlike standard equipment, it was concluded typical flywheel-based devices do not induce strains upon bone of a sufficient magnitude and rate to evoke osteogenesis [6].

Flywheel-based resistive exercise has not ameliorated bone losses in disuse models without concurrent albuterol [15] or palmidronate [16] administrations. Perhaps the most noteworthy flywheel-based apparatus is the Advanced Resistive Exercise Device (ARED) that was designed for use aboard at The International Space Station [17]. The ARED uses pneumatic cylinders as its primary form of resistance, but its operation includes flywheels to simulate the inertial properties of standard resistive exercise equipment [17]. Hip and spine bone mineral density changes were examined in healthy ambulatory subjects who received either a 16-week ARED or standard resistive exercise intervention with no crossover [18]. Study results include similar bone mineral density gains to both groups [18]. However the authors

*Corresponding author: JF Caruso, Exercise and Sports Science Program, The University of Tulsa, Tulsa, Oklahoma, USA, E-mail: john-caruso@utulsa.edu

Received May 06, 2012; Accepted May 08, 2012; Published May 12, 2012

Citation: Caruso JF (2012) Standard versus Flywheel-Based Resistive Exercise. J Sports Med Doping Stud 2:e110. doi:10.4172/2161-0673.1000e110

Copyright: ( 2012 Caruso JF. This is an open-access article distributed under the terms of the Creative Commons Attribution License, which permits unrestricted use, distribution, and reproduction in any medium, provided the original author and source are credited. 
acknowledged, despite their optimistic results, that the efficacy of the ARED to prevent bone losses in a disuse model remains to be validated [18]. In summary while flywheel-based resistive exercise improves muscle and strength-related outcomes, bone is less responsive to the mechanical loads they impart. To date, only when they are combined with pharmaceutical interventions $[13,15,16]$, or play a secondary role to pneumatic resistance [17], do flywheel-based equipment evoke bone accretion. Due to its popularity, as well as the faith persons place in flywheel-based resistive exercise, continued research with this modality is warranted to produce a better understanding of its efficacy to improve performance- and health-related outcomes.

\section{References}

1. Mitka M (2007) Health care quality varies widely across the states. JAMA 298: 276.

2. Fleck SJ, Kraemer WJ (1987) Designing resistance training programs. ( $2^{\text {nd }}$ edn) Human Kinetics, USA.

3. Akima H, Kubo K, Imai M, Kanehisa H, Suzuki Y, et al. (2001) Inactivity and muscle: effect of resistance training during bed rest on muscle size in the lower limb. Acta Physiol Scand 172: 269-278.

4. Bamman MM, Hunter GR, Stevens BR, Guilliams ME, Greenisen MC (1997) Resistance exercise prevents plantar flexor deconditioning during bed rest. Med Sci Sports Exerc 29: 1462-1468

5. Berg HE, Tesch PA (1998) Force and power characteristics of a resistive exercise device for use in space. Acta Astronaut 42: 219-230.

6. Caruso JF, Hamill JL, Hernandez DA, Yamauchi M (2005) A comparison of isoload and isoinertial leg press training on bone and muscle outcomes. $J$ Strength Cond Res 19: 592-598.

7. Alkner BA, Tesch PA (2004) Efficacy of a gravity-independent resistance exercise device as a countermeasure to muscle atrophy during 29-day bed rest. Acta Physiol Scand 181: 345-357.

8. Alkner BA, Tesch PA (2004) Knee extensor and plantar flexor muscle size and function following 90 days of bed rest with or without resistance exercise. Eur J Appl Physiol 93: 294-305

9. Tesch PA, Trieschmann JT, Ekberg A (2004) Hypertrophy of chronically unloaded muscle subjected to resistance exercise. J Appl Physiol 96: 14511458

10. Caruso J, Hamill J, Yamauchi M, Mercado D, Cook T, et al. (2005) Albutero aids resistance exercise in reducing unloading-induced ankle extensor strength losses. J Appl Physiol 98: 1705-1711.

11. Caruso JF, Hamill JL, Yamauchi M, Mercado DR, Cook TD, et al. (2004) Albuterol helps resistance exercise attenuate unloading-induced knee extensor losses. Aviat Space Environ Med 75: 505-511.

12. Shackelford LC, LeBlanc AD, Driscoll TB, Evans HJ, Rianon NJ, et al. (2004) Resistance exercise as a countermeasure to disuse-induced bone loss. J App Physiol 97: 119-129.

13. Cavanaugh PR, Licata AA, Rice AJ (2005) Exercise and pharmacological countermeasures for bone loss during long-duration space flight. Gravit Space Biol Bull 18: 39-58.

14. Schneider SM, Amonette WE, Blazine K, Bentley J, Lee SM, et al. (2003) Training with the International Space Station interim resistive exercise device. Med Sci Sports Exerc 35: 1935-1945.

15. Caruso JF, Hamill JL, Yamauchi M, Cook TD, Mercado DR, et al. (2004) Can albuterol help resistance exercise attenuate unloading-induced bone loss? J Strength Cond Res 18: 753-759.

16. Rittweger J, Frost HM, Schiessl H, Ohshima H, Alkner B, et al. (2005) Muscle atrophy and bone loss after 90 days' bed rest and the effects of flywhee resistive exercise and pamidronate: results from the LTBR study. Bone 36 1019-1029.

17. Bentley JR, Leach MA, McCleary F, Smith C, Norcross J, et al. (2006) Advanced Resistive Exercise Device (ARED) Man-In-The-Loop Test (MILT). NASA/TP, USA

18. Loehr JA, Lee SM, English KL, Sibonga J, Maddocks MJ, et al. (2008) Bone mineral density adaptations of the hip and spine to training with the advanced resistive exercise device and with free weights in ambulatory subjects. Med Sc Sports Exerc 40: S303. 